\title{
Internal mammary harvesting: the long-lasting history and harvesting techniques
}

\author{
Amer Harky $^{1}$ and Jalal BinSaeid ${ }^{1}$ \\ ${ }^{1}$ Liverpool Heart and Chest Hospital NHS Foundation Trust
}

May 14, 2020

Internal mammary harvesting: the long-lasting history and harvesting techniques

Running Head: Internal mammary artery

Amer Harky ${ }^{1,2}$, Jalal BinSaeid ${ }^{1}$

1. Department of Cardiothoracic Surgery, Liverpool Heart and Chest, Liverpool, UK

2. University of Liverpool, Liverpool, UK

\section{Corresponding author}

Amer Harky

MRCS, MSc

Department of Cardiothoracic Surgery

Liverpool Heart and Chest

Liverpool, UK

e-mail: aaharky@gmail.com

tel: +44-151-600-1616

Funding: none obtained

Conflict of Interest: None obtained

Key words: Internal mammary, technique, harvesting

Dear Editor,

In our previous article [1] we have explained the different techniques of harvesting the internal mammary artery (IMA) and current literature evidence behind each method. Indeed, the skeletonized technique was introduced at later stage when compared to the history of pedicled technique; the former was only described first by Keeley et al. in 1987 [2]. He postulated that this technique will provide a longer conduit length and therefore the chance of higher number of anastomoses to be performed on the diseased coronary arteries.

It is well established in literature, studies from human and animals, that skeletonized IMA is associated with lower sternal wound infection and this is attributed most likely to the fact that there is less trauma to the chest wall, and the possible lack of sternal hypoperfusion during skeletonized harvesting approach which plays key role in such serious complication. [3]. Despite most studies have shown rather short and transient mal perfusion picture in the first 5-7 days, pedicled harvesting was still responsible for early sternal 
complication which diverted the attention towards skeletonised harvesting technique in addition to the fact that more conduit length can be obtained with this technique. [4]

It is paramount to understand that cardiac surgery including conduit harvesting is evolving, whether it is related to adverse outcomes of the practice or evolution of new techniques that provides safer, more effective and reliable approaches. This is reflected in all aspects of cardiac surgery, as such including the harvesting of IMA whether harvested as pedicled, skeletonized or semi-skeletonized approach. [5]

\section{References:}

1. Yim D, Wong WYE, Fan KS, Harky A. Internal mammary harvesting: Techniques and evidence from the literature. J Card Surg. 2020;35(4):860-7

2. Keeley SB. The skeletonized internal mammary artery. AnnThorac Surg 1987;44:324-5.

3. Deja MA, Woś S, Gołba KS, et al. Intraoperative and laboratory evaluation of skeletonized versus pedicled internal thoracic artery. Ann Thorac Surg. 1999;68(6):2164-2168.

4. Cheng K, Rehman SM, Taggart DP. A Review of Differing Techniques of Mammary Artery Harvesting on Sternal Perfusion: Time for a Randomized Study? Ann Thorac Surg. 2015 Nov;100(5):1942-53. doi: 10.1016/j.athoracsur.2015.06.087.

5. Harky A, Sankaranarayanan V, Kong QG. Internal mammary artery: the primary conduit for surgical revascularization. Coron Artery Dis. 2020 Apr 16. doi: 10.1097/MCA.0000000000000895. 